\title{
Evaluation of immunochromatographic assay for serodiagnosis of bovine brucellosis in Gezira State, Sudan
}

\author{
A. M. El-Eragi ${ }^{1}$, Manal H. Salih ${ }^{1}$, Mihad F. E. M. Alawad ${ }^{2}$ and K. B. Mohammed $^{1}$ \\ 1. Department of Pathology and Diagnosis, Veterinary Research Institute. P. O. Box 8067 (ALAmart), Khartoum, Sudan; \\ 2. Department of Brucella, Veterinary Research Institute. P. O. Box 8067 (ALAmart), Khartoum, Sudan. \\ Corresponding author: K. B. Mohammed, email: khalidbabiker41@gmail.com \\ AME: eleragi@gmail.com, MHS: manalsalih9@gmail.com, MFEMA: mihadscope@yahoo.com \\ Received: 15-02-2014, Revised: 02-05-2014, Accepted: 08-05-2014, Published online: 11-06-2014
}

doi: $10.14202 /$ vetworld.2014.395-397

How to cite this article: El-Eragi AM, Salih MH, Alawad MFEM and Mohammed KB (2014) Evaluation of immunochromatographic assay for serodiagnosis of bovine brucellosis in Gezira State, Sudan, Veterinary World 7(6): 395-397.

\begin{abstract}
Aim: To assess the diagnostic value of the Immunochromatographic Assay (ICA) for serodiagnosis of bovine brucellosis and comparing results with those obtained from Rose Bengal Plate Test (RBPT) and Indirect Enzyme Linked Immunsorbent Assay (iELISA).

Materials and Methods: In this study, 40 bovine sera were subjected to serological tests for bovine brucellosis using RBPT, iELISA and ICA using Anigen Rapid B. Brucella Ab test kit.

Results: Out of the 40 bovine sera examined, antibodies against Brucella were detected in $24(60 \%), 27(67.5 \%)$ and $20(50 \%)$ samples by by RBPT, iELISA and ICA respectively. The kappa value between iELISA and ICA was 0.45 and that between RBPT and iELISA was 0.53 . The sensitivity for RBPT and ICA was $(76 \%)$ and $(59.26 \%)$ respectively while specificity was $(57.14 \%)$ and $(80 \%)$ for these two tests respectively.

Conclusion: These findings indicated that ICA was more specific than RBPT while the latter was more sensitive. Both tests showed almost moderate agreement.
\end{abstract}

Keywords: bovine, brucellosis, immunochromatographic, serodiagnosis, Sudan.

\section{Introduction}

Brucellosis remains a major zoonosis worldwide [1-3]. Particularly in developing countries the disease may have important economic, veterinary and public health consequences [4-7]. Abortion, placentitis, epididymitis and orchitis are the most common clinical manifestations in animals [8]. Brucellosis is readily transmissible to humans, causing acute febrile illness (undulant fever) which may progress to a more chronic form and can also produce serious complications affecting the musculo-skeletal, cardiovascular, and central nervous systems [9].

Clinical diagnosis of brucellosis is not easily achieved. Laboratory testing is therefore very important for a correct identification of the disease in humans and for the detection and confirmation in animals [8]. The diagnostic method known to produce the best results in term of specificity is the isolation of Brucella organisms from the suspected animals. However, this method is expensive, cumbersome, has a limited sensitivity and it is difficult to apply in large scale control campaigns [10]. Accordingly the indirect diagnosis of disease based on serological tests is of choice in the control programmes. The standard Rose Bengal Plate Test (RBPT) is the main serological test used to detect antibodies against B. abortus and $B$.

Copyright: The authors. This article is an open access article licensed under the terms of the Creative Commons Attribution License (http://creativecommons.org/licenses/by/2.0) which permits unrestricted use, distribution and reproduction in any medium, provided the work is properly cited. melitensis infections. This test has been used for several decades and has proven useful in eradication of bovine brucellosis in some countries [11]. The enzymelinked immunosorbent assay (ELISA) is a highly specific and sensitive diagnostic assay since it directly detect antibody and has minimal or no false positive reactions of agglutination test [10].

More recently, the convenience and speed of the test have been achieved by a novel concept of immunochromatographic (ICA) assay which is a simplified version of ELISA [12,13]. The objective of this study was to assess the diagnostic value of the ICA device for serodiagnosis of bovine brucellosis and compare results with those obtained from RBPT and Indirect Enzyme Linked Immunsorbent Assay (iELISA)

\section{Materials and Methods}

Ethical approval: The investigation was carried out in accordance with the Sudan animal welfare laws.

Sample collection: 40 serum samples were received from Veterinary Research Institute, Department of Brucella. These samples were collected from apparently healthy crossbred (Friesian x local Butana eco-type), 2 years or older dairy cows in Gezira State.

\section{Serological tests}

Rose Bengal Plate test: RBPT was performed with standard antigen locally produced in Veterinary Research Institute, Department of Brucella according to OIE [9]. Serum samples and antigens were removed 


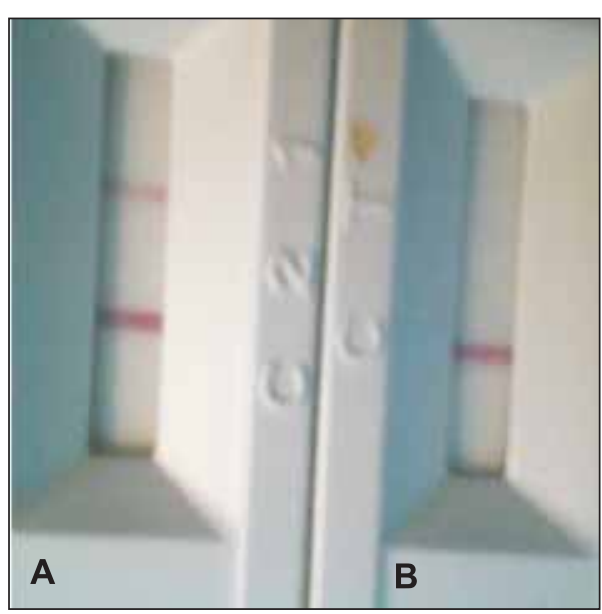

Table-1: Results of bovine serum tested for brucellosis by RBPT, ICA and iELISA.

\begin{tabular}{lccc}
\hline Type of test & Positive result & Negative result & Percentage \\
\hline RBPT & 24 & 16 & 60 \\
ICA & 20 & 20 & 50 \\
iELISA & 27 & 13 & 67.5 \\
\hline
\end{tabular}

Table-2: The sensitivity, specificity and statistical analysis of ICA and RBPT in comparison with iELISA.

\begin{tabular}{lccc}
\hline Diagnostic test & Sensitivity \% & Specificity \% & Kappa \\
\hline RBPT & 76 & 57.14 & 0.53 \\
ICA & 59.26 & 80 & 0.45 \\
\hline
\end{tabular}

Figure-1: Bovine Brucella Immunochro-matographic assay, (A) positive result, (B) negative result.

from the freezer, refrigerator repectively and the antigens were allowed to acclimatize to room temperature. The test was done by dispensing $0.03 \mathrm{ml}$ of each serum to be tested to an enamel plate. The same quantity of Rose Bengal antigen was added to each serum and mixed by plastic rod, then agitated by rocker for $4 \mathrm{~min}$, after that the test was read. Appearance of any agglutination was considered positive.

ICA: This test was applied using the Anigen Rapid $B$. Brucella Ab kit (BIONOTE 2-9, Seogu-dong, Hwaseong-si, Gyeonggi-do, Korea (DOC.No: 123012) which is used for the qualitative detection of Brucella abortus antibody in whole blood, plasma, serum and milk. Twenty microliters of the serum was added to the sample well followed by 3 drops of the assay diluent. The test result was interpreted after 20 minutes. If the test is working properly the control line (C) will appear in the left section of the result device window (T) as a purple band. The presence of two purple color bands within the device window $(\mathrm{C})$ and (T) indicate a positive result (Figure-1A). The presence of only one purple color bands within the device window (C) indicate a negative result (Figure-1B).

ieLISA: The Anigen B. Brucella Ab ELISA 2.0 ( BIONOTE 2-9, Seogu-dong, Hwaseong-si, gyeonggido, Korea (DOC.No: 12301-2) ) is an iELISA for the qualitative detection of Brucella abortus antibody in serum and plasma. The test was performed as described by the manufacturer.

Statistical analysis: Data analyses were carried out using a statistical software program (SPSS for windows, version 17.01). The agreement between serological tests was calculated using kappa analysis.

Sensitivity $=$ true positive $/$ true positive + false negative Specificity $=$ true negative/false positive + true negative

\section{Results}

Out of 40 serum samples examined by RBPT, iELISA, and ICA (Figure-1), antibodies against Brucella were found in 24 samples (60\%), 27 samples $(67.5 \%)$ and 20 samples $(50 \%)$ by these tests respec- tively (Table-1).

The result presented in Table- 2 showed that the sensitivity for RBPT and ICA was (76\%) and (59.26\%) respectively while specificity was $(57.14 \%)$ and $(80 \%)$ respectively. There is agreement of ICA $(\mathrm{k}=0.45)$ and $\operatorname{RBPT}(\mathrm{k}=0.53)$ in relation to iELISA.

\section{Discussion}

In this study, RBPT was found to be more sensitive than ICA but ICA was more specific than RBPT as ICA can detect both IgG and IgM antibodies to Brucella in animals. The result is fairly similar to earlier studies [11, 14].

In the present study, it was noticed that some samples which were found to be positive by RBPT, proved to be negative by iELISA and ICA. This may be attributed to cross reaction by some bacteria such as Escherichia coli, Salmonella dublin, Yersinia enterocolitica 0:9 and others in the body fluids and secretions [15-17] or background antibody levels due to earlier exposure or vaccination thus causing faults or error in the interpretation of the results. Furthermore the great number of false positive detected by RBPT was due to the activity of specific and non-specific antibodies and therefore a combination of serological tests should be included to reduce the number of both false negative and false positive serological reaction. This agrees with Bronsvoort et al. [18] who stated that although some diagnostic or screening tests are referred to as "gold standard" but it need the use of a more specific test to confirm any positive reactors. Radulescu et al. [19] reported that diagnosis of brucellosis by serological study largely depends on the use of two or more tests and than the use of a more specific test to confirm any positive animal. Single test is not recommended since this could not detect all positive reactors [19].

The ICA has several practical advantages that allows testing on the spot and this makes it the method of choice when testing animals from nomadic and other migratory populations [20]. Practical advantages include the use of the ICA does neither requires specific training, expertise, electricity nor expensive equipment. 
Also this assay devices may be stored without the need for refrigeration and the test results are obtained almost instantaneously and by visual inspection with the unaided eye [20]. Furthermore, the components of the ICA are well-standardized which for instance is not the case with the antigen used in the RBPT that requires careful titration [21]. By using the ICA as a field test identification and tracing of animals and their owners, it is much less problematic and intervening measures to control the disease could be started without delay with less risk of further transmission and spread of infection [20]. Horie et al. [22], Yang et al. [23] and Senthilkumar et al. [24] concluded that the developed ICA is immunodiagnostic assay, simple, rapid, economical and suitable for large-scale screening in endemic areas.

\section{Conclusion}

RBPT revealed the high rate of sensitivity suggesting the use of this test as screening test on bovine brucellosis. ICA showing the high rate of specificity could be used for confirmation of positive samples screened by RBPT.

\section{Authors' contributions}

AME implemented the study design and revised the manuscript. MFEMA collected the samples and analyzed the data. MHS, MFEMA, KBM carried out immunochromatographic assay, iELISA, statistical analysis and drafted the manuscript. All authors read and approved the final manuscript.

\section{Acknowledgements}

The authors acknowledge The Director of Veterinary Research Institute, Khartoum, Sudan for funding this research.

\section{Competing interests}

The authors declare that they have no competing interests.

\section{References}

1. Baek, B.K., Lim, C.W., Rahman, M.S., Kim, C. H., Oluoch, A. and Kakoma, I. (2003) Brucella abortus infection in indigenous Korean dogs. Can. J. Vet. Res., 67:312-314.

2. Kakoma, I., Oluoch, A.O., Baek, B.K., Rahman, M.S and Matsuda, K. (2003). More attention warranted on Brucella abortus in animals. J. Am. Vet. Med. Assoc., 222: 284.

3. WHO (1986) Joint FAO/WHO Expert Committee on Brucellosis. World Health Organ Tech Rep Ser., 740:1-132.

4. Franco, M.P., Mulder, M., Gilman, R.H. and Smits, H.L. (2007) Human brucellosis. Lancet Infect. Dis., 7: 775-786.

5. Godfroid, J., Cloeckaert, A., Liautard, J.P., Kohler, S., Fretin, D., Walravens, K, Garin Bastuji, B. and Letesson, J.J. (2005) From the discovery of the Malta fever's agent to the discovery of a marine mammal reservoir, brucellosis has continuously been a reaemerging zoonosis. Vet. Res., 36:313-326

6. Pappas, G., Papadimitriou, P., Akritidis, N., Christou, L. and Tsianos, E.V. (2006) The new global map of human brucellosis. Lancet Infect. Dis., 6: 91-99.

7. Smits, H.L. and Kadri, S.M. (2005) Brucellosis in India: a deceptive infectious disease. Indian J. Med. Res.,122: 375-384.

8. Poiester, F. P., Nielsen, K., Samartino, L. E., and Yu, W. L. (2010) Diagnosis of brucellosis. Open Vet. Sci. J., 4: 46-60.

9. Office International des Epizooties (OIE) (2009) OIE
Terrestrial Manual, Chapter 2.4.3., Bovine brucellosis. http://www.oie.int/fileadmin/Home/eng/Health standards/tahm//2.0403_ BOVINE _BRUCELL. Pdf. Accessed on 07-06-2017.

10. Jabbar, A.A.,AL-Sa'aidi, M.A. and AL-Rodh, A.A.N. (2012) Clinical, Serological, Hormonal, Bacteriological and Molecular Detection of Brucellosois in Aborted Cows and Buffaloes. Int. Conference on Applied Life Science, Turkey.

11. Nielsen, K., Gall, D., Smith, P., Balsevicius, S., Garrido, F. Ferrer, M. D., Biancifiori, F., Dajer, A., Luna, A., Samartino, L., Bermudez, R., Moreno, F., Renteria, T. And Corral, A. (2004) Comparison of serological tests for the detection of ovine and caprine antibody to Brucella melitensis. Rev. Sci. Tech., 23: 979-987.

12. Lou, S.C., Patel, C., Ching, S. and Gordon, J.(1993) Onestep competitive immunochromatographic assay for semiquantitative determination of lipoprotein (a) in plasma. Clin. Chem., 39: 619-624.

13. Birnbaum, S., Uden, C., Magnusson, C. G. and Nilsson, S. (1992) Latex-based thin-layer immunoffmity chromatography for quntitation of protein analytes. Anal. Biochem., 206 : 168-171.

14. Abdoel, T.H. and Smith, H.L. (2007). Rapid latex agglutination test for serodiagnosis of human brucellosis. Diagn. Microbiol. Infect. Dis., 57(2):123-128.

15. Diaz-Aparicio, E., Aragon, V., Marin, C., Alonso, B., Font, M., Moreno, E., Perez-Ortiz, S., Blasco, J.M., Diaz, R. and Moriyon, I. (1993) Comparative analysis of Brucella serotype $\mathrm{A}$ and $\mathrm{M}$ and Yersinia enterocolitica 0:9 polysaccharides for serological diagnosis of brucellosis in cattle, sheep and goats. J. Clin. Microbiol., 31:3136-3141.

16. Hilbink, F., Fenwick, S.G., Thompson, E.J., Kittelberger, R., Penrose, M., and Ross, G.P. (1995) Non-specific seroreactions against Brucella abortus in ruminants in New Zealand and the presence of Yersinia enterocolitica 0:9, NZ. Vet. J., 3(43): 175-178.

17. Weynants, V., Tibor, A., Denoel, P.A., Saegerman, C. and Godfroid, J. (1996) Infection of cattle with Yersinia enterocolitica 0:9 a cause of false positive serological reaction in bovine brucellosis diagnostic test. Vet. Microbiol.,48: 101-112.

18. Bronsvoort, B. M., Koterwas, B., Land, F., Handel, I.G., Tucker, J., Morgan, K. L., Tanya, V. N. and Smits, H. L. (2009) Comparison of a Flow Assay for Brucellosis Antibodies with the reference" cELISA" test in West African Bos indicus. Plos One., 4(4): 5221.

19. Radulescu, R.A., Petriceanu, G., Ragalie, A. and Gutu, E. (2007) Comparative evaluation of serological assays for brucellosis diagnosis. Rev. Rom. Med. Vet., 17: 83-92.

20. Abdoel, T., Dias, I. T, Cardoso, R. and Smits, H. L. (2008) Simple and rapid field tests for brucellosis in livestock. Vet. Microbiol., 130:312-319.

21. Blasco, J.M., Garin-Bastuji, B., Marin, C.M., Gerbier, G., Fanlo, J., Jimenez de Bagues, M.P. and Cau, C. (1994) Efficacy of different Rose Bengal and complement fixation antigens for the diagnosis of Brucella Melitensis infection in sheep and goats. Vet. Rec., 134: 415-420.

22. Horie, M., Ogawa, H., Yamada, K., Hara, H., Bui, V.N., Awad, S. S., Yoshikawa, R., Tusukamato, K., Yamaguchi, S., Nakamura, K. and Imai, K. (2009) Alatex agglutination test using a recombinant nucleoprotein for detection of antibodies against avian influenza virus. J. Virol. Methods, 161(2): 259-264

23. Yang, J., Hua, Q., Chen, H., Lv, J., Chen, B. And Ruan, Z. (2010) A rapid assay for detecting antibody against Bluetongue virus with a latex agglutination test using recombinant VP7 antigen. J. Vet Diagn Invest., 22(2): 242-4.

24. Senthilkumar, T., M. Subathra, M., Phil, M., Ramadass, P. and Ramaswamy, V. (2009) Rapid serodiagnosis of leptospirosis by latex agglutination test and flow - through assay. Indian J. Med. Microbiol., 26(1): 45-49.

$* * * * * * * *$ 